\title{
On the Solubility of Gallium Nitride in Supercritical Ammonia-Sodium Solutions
}

\author{
$\underline{\text { Steven Griffiths }}{ }^{*}$, Siddha Pimputkar, James S. Speck, Shuji Nakamura \\ Materials Department, University of California, Santa Barbara, CA 93106, U.S.A. \\ *Corresponding Author: shgriffiths@engineering.ucsb.edu
}

\section{Abstract}

Due to the disparity between observed gallium nitride $(\mathrm{GaN})$ growth under conditions for which literature reports normal solubility, $\mathrm{GaN}$ solubility in supercritical $\mathrm{NH}_{3}-\mathrm{Na}$ containing solutions was re-evaluated. Isothermal gravimetric experiments on polycrystalline GaN were performed in the temperature range $\left(\mathrm{T}=415-650^{\circ} \mathrm{C}\right)$ for which retrograde growth of $\mathrm{GaN}$ routinely occurs $(\mathrm{P}$ $\approx 200 \mathrm{MPa}$, molar $\mathrm{NH}_{3}: \mathrm{Na}$ fill ratio $\left.=20: 1\right)$. Two previously-unreported error contributions to the gravimetric determination of GaN solubility were identified: Ga-alloying of exposed Nicontaining components, and the presence of a dense, Ga-absorbing Na-rich, second phase under these conditions. Due to the inability to measure Ga-alloying of the exposed autoclave wall for each experiment, considerable scatter was introduced in the refined GaN solubility curve. No clear dependence of GaN solubility on temperature was resolvable, while most solubility values were determined to be within a band of 0.03-0.10 mol. \% GaN, normalized by fill $\mathrm{NH}_{3}$. 


\section{Keywords}

- A1. Solubility

- A1. Mineralizers

- A2. Ammonothermal

- B1. Nitrides

- B1. Supercritical ammonia solutions 


\section{Introduction}

Gallium nitride $(\mathrm{GaN})$ and its alloys with indium nitride $(\mathrm{InGaN})$ and aluminum nitride ( $\mathrm{AlGaN})$ have enabled energy-efficient solid state lighting and power switching technologies. White light emitting diode (LED) technology has made a lasting, positive impact on society, yet commercial LED performance is still hampered by fundamental barriers, which include efficiency droop of blue LEDs for phosphor-converted designs, and inefficient green emitters (the "green gap") for color-mixed LED light sources [1]. One potential solution to address these barriers is to shift from heteroepitaxial growth on foreign substrates (such as $\alpha-\mathrm{Al}_{2} \mathrm{O}_{3}, \mathrm{Si}, \mathrm{SiC}$, etc.) to homoepitaxial growth on native GaN substrates. Nonpolar (and semipolar) substrate orientations cut from bulk GaN boules enable high quality growth of thick quantum wells, resulting in devices with lower carrier density in the active region and zero (or reduced) spontaneous and piezoelectric polarization fields, and thus higher efficiency at high current density and longer wavelengths due to reduction of non-radiative Auger recombination [1][2][3][4]. Furthermore, laser diodes (LDs) have a potential role to play in solid state lighting because they do not suffer from current efficiency droop above threshold current, they emit collimated light (lower beam divergence over long distances), and they allow for increased light emission per wafer area than LEDs. However, GaN substrates are essential for LD production, as the deleterious effects of high dislocation density in heteroepitaxial films reduces laser lifetime to impractical values for commercial applications $\left(\sim 10^{3}\right.$ hours for epitaxial lateral overgrowth (ELOG) on $\alpha-\mathrm{Al}_{2} \mathrm{O}_{3}$ substrates with $10^{6}-10^{7} \mathrm{~cm}^{-2}$ dislocation density in the epitaxial layers) [5][6].

An ammonia $\left(\mathrm{NH}_{3}\right)$ solution growth technique, known as the ammonothermal method, has received great interest from academia and industry alike for its ability to produce bulk GaN boules of exceedingly high quality. Conventional ammonothermal growth of $\mathrm{GaN}$ proceeds by 
establishing a temperature gradient between two zones ("dissolution" zone and "growth" zone) of an isobaric autoclave. The autoclave is filled with a $\mathrm{NH}_{3}$ solution, enriched with additional chemical species called mineralizers to increase the solubility of $\mathrm{GaN}$ in the system, and is heated above its critical point $\left(\mathrm{T}>132{ }^{\circ} \mathrm{C}, \mathrm{P}>11.3 \mathrm{MPa}\right)$. Polycrystalline $\mathrm{GaN}$ source material is dissolved in the dissolution zone at a fluid temperature of $T_{D}^{\text {int }}$, and is transported to the growth zone, where the dissolved GaN crystallizes on single crystal GaN seeds at a fluid temperature of $T_{G}^{\text {int }}$. Traditionally, due to the moderately high pressure $(\geq 200 \mathrm{MPa})$ and temperature $\left(>500{ }^{\circ} \mathrm{C}\right)$ inherent to the technique, $T_{D}^{\text {int }}$ and $T_{G}^{\text {int }}$ are not typically measured or controlled directly, rather an external wall temperature gradient of the autoclave $\left(T_{G}^{\text {ext }}-T_{D}^{\text {ext }}\right)$ is established and controlled. The ammonothermal method is pursued with either acidic or basic chemistries. In acidic ammonothermal growth, halide species (such as ammonium fluoride $\left(\mathrm{NH}_{4} \mathrm{~F}\right)$, ammonium chloride $\left(\mathrm{NH}_{4} \mathrm{Cl}\right)$, etc. $)$ are added as mineralizers, thereby shifting the dissociation reaction of $\mathrm{NH}_{3}$ towards ammonium $\left(\mathrm{NH}_{4}{ }^{+}\right)$; whereas, in basic ammonothermal growth, alkali or alkaline earth species (such as sodium (Na), potassium amide $\left(\mathrm{KNH}_{2}\right)$, etc.) are added as mineralizers, thereby shifting the dissociation reaction of $\mathrm{NH}_{3}$ towards amide $\left(\mathrm{NH}_{2}{ }^{-}\right)$. Both techniques have demonstrated growth of 2 inch diameter boules, with threading dislocation density as low as $10^{3}-10^{4} \mathrm{~cm}^{-2}$, but the state-of-the-art polar $\langle 0001\rangle$ and nonpolar $\langle 10 \underline{10}\rangle$ growth rates (the highest of which are near $1 \mathrm{~mm} /$ day) are thought to be too slow to supplant hydride vapor phase epitaxy (HVPE, with growth rates $>2.4 \mathrm{~mm} /$ day) as the industry-preferred growth method [7][8][9][10][11][12][13].

One potential method to increase growth rates in the ammonothermal system is to increase the chemical potential driving force for dissolved GaN to crystallize on seeds in the growth zone. The chemical potential driving force $(\Delta \mu)$ is given by Equation 1, in which $\gamma$ refers to the 
activity coefficient of $\mathrm{GaN}$ in the supercritical $\mathrm{NH}_{3}$ solution at the specified temperatures $\left(\gamma_{G a N}^{N H_{3}\left(T_{D}^{i n t}\right)}, \gamma_{G a N}^{N H_{3}\left(T_{G}^{i n t}\right)}\right)$, and $S$ refers to the solubility of GaN in the supercritical $\mathrm{NH}_{3}$ solution at the specified temperatures $\left(S_{G a N}^{N H_{3}\left(T_{D}^{i n t}\right)}, S_{G a N}^{N H_{3}\left(T_{G}^{i n t}\right)}\right)$. Therefore, understanding solubility in the ammonothermal system is paramount in understanding the chemical potential driving force for bulk GaN crystal growth.

Equation 1

$$
\Delta \mu=R T_{G}^{i n t} \ln \left(\frac{\gamma_{G a N}^{N H_{3}\left(T_{D}^{i n t}\right)} * S_{G a N}^{N H_{3}\left(T_{D}^{i n t}\right)}}{\gamma_{G a N}^{N H_{3}\left(T_{G}^{i n t}\right)} * S_{G a N}^{N H_{3}\left(T_{G}^{i n t}\right)}}\right)
$$

Many research groups have studied the solubility of $\mathrm{GaN}$ in both the acidic ammonothermal environment (with $\mathrm{NH}_{4} \mathrm{~F}$ [14], $\mathrm{NH}_{4} \mathrm{Cl}$ [14][15][16], $\mathrm{NH}_{4} \mathrm{Br}$ and $\mathrm{NH}_{4} \mathrm{I}$ [17] as mineralizers), and in the basic ammonothermal environment (with $\mathrm{KNH}_{2}$ [18][19] and $\mathrm{NaNH}_{2}$ [20] as mineralizers). For reference, all reported solubility curves measured in the basic ammonothermal environment are summarized in Figure 1. Most GaN solubility experiments have consisted of gravimetric measurements, in which the mass of GaN (either polycrystalline material or HVPE single crystal seeds) added to the autoclave is measured before and after being exposed to an isothermal $\mathrm{NH}_{3}$ solution, with the resulting mass change considered to have been dissolved in the $\mathrm{NH}_{3}$ solution during the experiment. The temperatures recorded for these solubility measurements typically refer to the temperature of the external wall of the autoclave. More recently, Schimmel et al. performed solubility measurements using an in situ X-ray tomography technique with internal temperature measurement capability, which could resolve dimensional changes of an HVPE seed in real time during etch back, thereby allowing for dynamic determination of the GaN solubility [14]. In general, it has been determined that acidic 
chemistry exhibits forward, or normal solubility with respect to temperature (i.e., increasing solubility with increasing temperature), whereas basic chemistry exhibits retrograde solubility with respect to temperature (i.e., decreasing solubility with increasing temperature). Notable exceptions to this trend exist for $\mathrm{NH}_{3}-\mathrm{NH}_{4} \mathrm{~F}$ solutions in the $550-650{ }^{\circ} \mathrm{C}$ range, and for $\mathrm{NH}_{3}$ $\mathrm{NH}_{4} \mathrm{Cl}$ solutions above $650^{\circ} \mathrm{C}$, both of which exhibit retrograde $\mathrm{GaN}$ solubility [11][21].

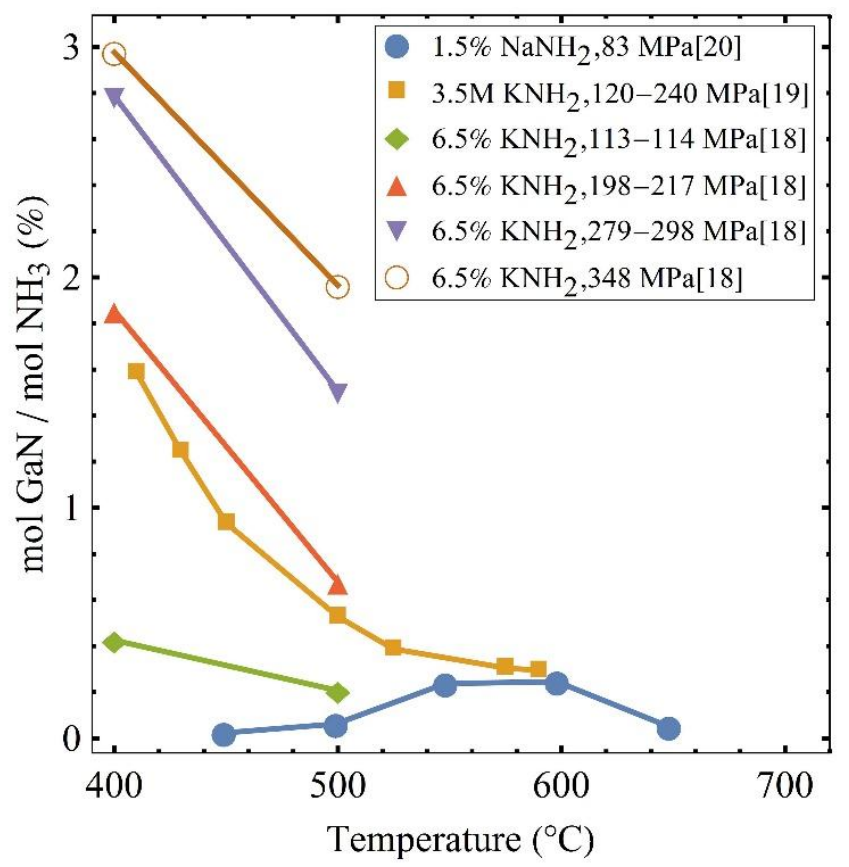

Figure 1. Summary of previously measured $\mathrm{GaN}$ solubility curves, normalized by $\mathrm{NH}_{3}$ amount, in basic ammonothermal systems as a function of temperature and pressure. "\%" mineralizer content refers to mol.\% mineralizer, normalized by $\mathrm{NH}_{3}$. Lines connecting data sets are added to guide the reader's eye, and are therefore not experimentally-determined. When appropriate, the original data submitted in the referenced work was digitized so as to ensure proper normalization by $\mathrm{NH}_{3}$ amount.

Our research group has developed expertise with bulk GaN growth in the supercritical $\mathrm{NH}_{3}-\mathrm{Na}$ system, including the ability to measure fluid temperatures in the dissolution $\left(T_{D}^{\text {int }}\right)$ and growth zones $\left(T_{G}^{i n t}\right)[12]$. It was found that crystal growth readily occurs at $T_{D}^{\text {int }}=451 \pm 8{ }^{\circ} \mathrm{C}$ and $T_{G}^{i n t}=$ $505 \pm 4{ }^{\circ} \mathrm{C}$, which implies retrograde solubility according to Equation 1, but corresponds to the region of forward solubility for the reported $\mathrm{NaNH}_{2}$ mineralizer solubility curve, shown in 
Figure 1 [20]. To resolve this discrepancy and better understand the fundamental driving force for $\mathrm{GaN}$ growth in basic ammonothermal systems, further investigations into the solubility of $\mathrm{GaN}$ in supercritical $\mathrm{NH}_{3}-\mathrm{Na}$ solutions are needed, with a focus on reducing sources of error for a more accurate assessment of the GaN solubility curve under relevant growth conditions: nominally isobaric conditions (peak total system pressure $\approx 200 \mathrm{MPa}$ ), with a constant molar $\mathrm{NH}_{3}: \mathrm{Na}$ fill ratio (20:1), and a varying internal (actual) fluid temperature $\left(415-650{ }^{\circ} \mathrm{C}\right)$. This paper presents the experimental determination of an improved GaN solubility curve, including corrections for two previously unreported sources of error in the gravimetric determination of GaN solubility.

\section{Experimental Methods}

The solubility of $\mathrm{GaN}$ in supercritical $\mathrm{NH}_{3}-\mathrm{Na}$ solutions was determined gravimetrically for systems under the relevant ammonothermal conditions previously identified. The mass change of a polycrystalline GaN charge $\left(w_{G a N}^{i}-w_{G a N}^{f}\right)$ was measured as a function of experiment soak time, autoclave free volume, and fluid temperature by performing 23 experiments under varying conditions. The apparent solubility of GaN, normalized by fill $\mathrm{NH}_{3}\left(S_{G a N}^{\text {Fill NH}}{ }_{3}\right)$, was determined in mol. \% according to Equation 2, in which $w_{N H_{3}}^{\text {fill }}$ refers to the weight of fill $\mathrm{NH}_{3}$ added to the autoclave, and $M W_{N_{3}}$ and $M W_{G a N}$ refer to the molecular weight of $\mathrm{NH}_{3}$ and GaN, respectively.

Equation 2

$$
S_{G a N}^{\text {Fill NH}_{3}}(\%)=\operatorname{mol~GaN} / \text { mol Fill } N_{3}(\%)=\frac{\left(w_{G a N}^{i}-w_{G a N}^{f}\right)}{w_{N H_{3}}^{f i l l}} * \frac{M W_{N H_{3}}}{M W_{G a N}} * 100
$$


Errors in determination of the mass change of the GaN charge were reduced by evacuating the supercritical $\mathrm{NH}_{3}-\mathrm{Na}$ solution at working pressure and temperature in less than 1 second, thereby nearly-instantaneously ending the experiment. This experimental design prevented the possibility of both the dissolution of the GaN charge or nucleation of dissolved GaN on the charge during cooldown.

A dense, white powder was always observed at the bottom of the autoclave after completion of the experiments. The powder is known to contain $\mathrm{Na}$ based on its reactivity with water. Evidence will be given which suggests that this powder crystallized from a liquid phase which was present (in addition to the supercritical $\mathrm{NH}_{3}-\mathrm{Na}$ solution) during the experiment. It is therefore assumed the $\mathrm{Na}$ was present in this second phase during the run as well, and therefore this phase will be referred to as the Na-rich phase throughout this work. Although the Na-rich phase was not analyzed in detail and is still under investigation, significant evidence has been presented in the liquid $\mathrm{NH}_{3}$ and ammonothermal literature to suggest that it is primarily composed of $\mathrm{NaNH}_{2}$ $[22][23][24]$.

Error in the determination of the temperature dependence of GaN solubility was reduced by directly probing the fluid temperature (rather than measuring the external autoclave wall temperature). Corrections to the apparent solubility curve were made by accounting for additional Ga sinks and sources in the autoclave. This was performed by analyzing the mass and chemical composition changes of autoclave components exposed to the ammonothermal environment, in addition to analyzing the mass and chemical composition of the Na-rich phase collected upon unloading the autoclave.

The polycrystalline GaN charge was sourced from Mitsubishi Chemical Co. (MCC), and was produced through parasitic growth on the susceptor and reactor walls during production of 
HVPE GaN boules. The polycrystalline pieces were crushed and sieved. Special care was taken to select $>3 \mathrm{~mm}$ pieces for the GaN charge in each experiment to avoid losing pieces while handling the material. The GaN charge mass was measured using a high precision balance (Mettler Toledo AB135-S/FACT, precision: $\pm 0.01 \mathrm{mg}$ ). The total mass of the GaN charge was kept above $7 \mathrm{~g}$ to ensure that the supercritical $\mathrm{NH}_{3}-\mathrm{Na}$ solution was saturated in dissolved $\mathrm{GaN}$, and that dissolution was not surface-limited. The GaN charge was added to a basket constructed of either nickel or nickel-chromium wire mesh (Ni-Cr, with composition 80-20 wt.\%, respectively). The GaN-containing basket was placed in a Rene $41 \mathrm{Ni}-\mathrm{Cr}$ superalloy autoclave on top of an Inconel 625 standoff, which elevated the basket to $\sim 2.5 \mathrm{~cm}$ above the bottom of the inner surface of the autoclave wall. Autoclaves of two different sizes were used for these experiments to ensure that the measured solubility did not depend on reactor dimensions (i.e., to prove that the measurements were intensive). The small autoclaves had internal free volumes of 60-70 mL, while the large autoclave had an internal free volume of $\sim 120 \mathrm{~mL}$.

After charging with the GaN-containing basket, the autoclave was placed in a nitrogen-filled glove box (ambient containing $\leq 1 \mathrm{ppm} \mathrm{O}_{2}$ and $\mathrm{H}_{2} \mathrm{O}$ ), where the $\mathrm{Na}$ (sourced from Alfa Aesar, 99.95\% metals basis purity) was prepared, weighed, and added to the autoclave according to procedures described in Ref. [12]. A high pressure, stainless steel head assembly was attached to the autoclave, which consisted of a feed-through containing an Inconel 625 sheathed Type $\mathrm{K}$ thermocouple (accuracy: $\pm 0.4 \%$ of reading), a pressure transducer (Honeywell model with \pm 3 $\mathrm{MPa}$ accuracy, or Omegadyne model with $\pm 0.3 \mathrm{MPa}$ accuracy), and a high pressure needle valve. The autoclave was sealed through compression of a nickel gasket (Ni 200/201, > 99\% purity). 
Once loaded and sealed, the autoclave assembly was taken out of the glove box and weighed with a precision balance (Sartorius MSA14202S, precision: $\pm 10 \mathrm{mg}$ ). The free volume of the autoclave assembly was measured to within $\pm 0.1 \mathrm{~mL}$ according to procedures described in Ref. [25]. The $\mathrm{NH}_{3}$ fill was estimated using the $\mathrm{NH}_{3}$ equation of state previously presented in the literature for the given free volume, target fluid temperature, and target peak total system pressure of $200 \mathrm{MPa}$ [25]. After filling the autoclave assembly with $\mathrm{NH}_{3}$ (Denko K.K.,

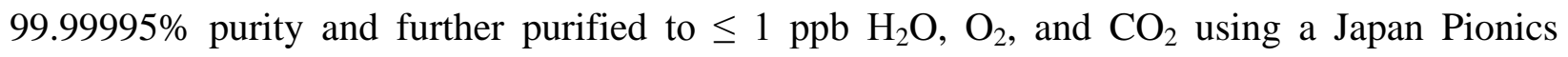
purifier and a SAES MicroTorr point-of-use purifier) and allowing it to warm to room temperature, a post-fill autoclave mass was recorded (Sartorius MSA14202S, precision: \pm 10 $\mathrm{mg}$ ) permitting an additional determination of the $\mathrm{NH}_{3}$ fill $\left(w_{\mathrm{NH}_{3}}^{\text {fill }}\right)$. The filled autoclave assembly was placed in a ceramic insulated, resistive heater stack and connected to exhaust via stainless steel tubing, a $0.5 \mu \mathrm{m}$ pore size line filter, and a normally-off, remote-controlled pneumatic valve.

Each experiment was executed by heating the autoclave assembly at a rate of $2{ }^{\circ} \mathrm{C} / \mathrm{min}$, and isothermally holding at a target soak temperature for $45-316$ hours. A schematic of the complete autoclave assembly at the soak temperature is shown in Figure 2, depicting the experimentally-supported, two-phase ammonothermal environment (supercritical $\mathrm{NH}_{3}-\mathrm{Na}$ solution phase and dense, Na-rich phase) as is described in the Results and Discussion section. At the conclusion of the desired soak time, the gaseous contents of the autoclave assembly were purged to exhaust by opening the remote-controlled pneumatic valve while the system remained at the soak temperature. The pneumatic valve was closed after approximately 10 seconds to prevent contamination from exhaust. The autoclave assembly was allowed to cool to room temperature over the course of $\sim 6$ hours, after which it was removed from the containment 
vessel. In some instances the autoclave assembly was opened in a nitrogen-filled glove box, where the remaining Na-rich powder at the bottom of the autoclave was collected for further analysis. It should be noted that $\mathrm{GaN}$ decomposition (whether in the supercritical $\mathrm{NH}_{3}-\mathrm{Na}$ solution, or in the evacuated autoclave post-purge) is expected to be negligible in the temperature range explored for this study $\left(<650{ }^{\circ} \mathrm{C}\right)[26]$.

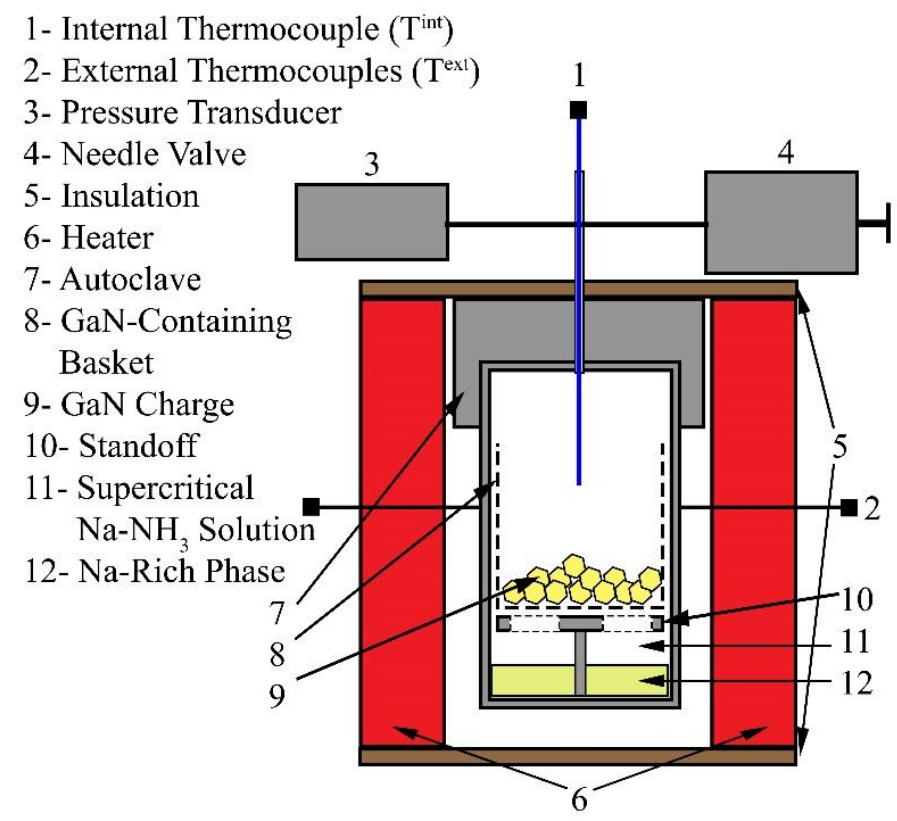

Figure 2. Autoclave assembly schematic for $\mathrm{GaN}$ solubility experiments in supercritical $\mathrm{NH}_{3}-\mathrm{Na}$ solutions at soak temperature. The GaN charge (9) is placed in a $\mathrm{Ni}$ (or Ni-Cr) GaN-containing basket (8), atop an Inconel 625 standoff (10) in a Rene 41 autoclave (7). After filling with $\mathrm{Na}$, a stainless steel head assembly is added to the autoclave. The head assembly includes a pressure transducer (3), needle valve (4), and Inconel 625-sheathed internal thermocouple (1). After filling with $\mathrm{NH}_{3}$, the autoclave assembly is placed in a resistive heater stack (6), in which external thermocouples monitor the external temperature of the autoclave wall (2), and around which insulation (5) is added, so as to maintain a uniform temperature throughout the autoclave volume. The autoclave assembly is then heated to the desired soak temperature, during which evidence suggests that the ammonothermal environment forms two distinct phases: a supercritical $\mathrm{NH}_{3}-\mathrm{Na}$ solution phase (11, in which the GaN charge is immersed) and a dense, Na-rich phase (12).

After opening the autoclave, all parts exposed to the supercritical $\mathrm{NH}_{3}-\mathrm{Na}$ solution were neutralized in a mixture of deionized water and isopropanol followed by sonication in pure deionized water, then isopropanol. Special care was taken during cleaning to look for pieces of 
$\mathrm{GaN}$ which may have fallen out of the basket, or spontaneously nucleated during the run, though no such pieces were ever observed (including in the tubing leading to the line filter, or in the line filter itself). After drying, the GaN charge, GaN-containing basket, and standoff were weighed (Mettler Toledo AB135-S/FACT, precision: $\pm 0.01 \mathrm{mg}$ ) to determine their mass change. Heavier parts (the autoclave, stainless steel head assembly, pressure transducer, internal thermocouple, high pressure tubing, and line filter) were weighed using a less precise balance (Sartorius MSA14202S, precision: $\pm 10 \mathrm{mg}$ ).

Cross-sectional samples of the 80-20 Ni-Cr wire mesh (composing some of the GaN-containing baskets) and the Inconel 625 standoff were prepared for chemical analysis. These samples were mounted in epoxy, polished, and then examined using a scanning electron microscope (SEM, FEI XL40 Sirion FEG Digital Scanning Microscope) with energy-dispersive X-ray spectroscopy (EDX) capability (Oxford INCA X-ray system).

The chemical composition of the Na-rich phase collected from the bottom of the autoclave postexperiment was investigated using an inductively coupled plasma (ICP) atomic emission spectrometer (Thermo Scientific, Model: iCAP 6300). The powder was removed from the autoclave in a nitrogen-filled glovebox, ground and mixed using a ceramic mortar and pestle, and weighed in the glovebox (Mettler Toldeo, Model: B303-S, Precision: $\pm 0.5 \mathrm{mg}$ ). A portion of the powder was digested in a solution composed of 2 wt.\% nitric acid in water. The ICP was calibrated using an acid blank ( 2 wt.\% nitric acid in water, with no dissolved solids added) and a certified $100 \pm 1 \mu \mathrm{g} / \mathrm{mL}$ standard solution for elements of interest ( $\mathrm{Ga}, \mathrm{Na}, \mathrm{Ni}, \mathrm{Cr}$, etc.) dissolved in a 2\% nitric acid matrix (High Purity Standards, Product: ICP-AM-MISA6, Lot: 1511720). A 10x dilution of the certified standard was performed to more narrowly bracket the concentration of dissolved solids in the unknown samples. 


\section{Results and Discussion}

Two previously-unreported errors for the gravimetric determination of the solubility of GaN in supercritical $\mathrm{NH}_{3}-\mathrm{Na}$ solutions were identified in our study. One error is due to the propensity of Ga to alloy with Ni-containing components in the system. A second error is due to Ga dissolution in the Na-rich phase present at the bottom of the autoclave during the experiment. The presence of a Na-rich phase implies that the solubility limit of $\mathrm{Na}$ in supercritical $\mathrm{NH}_{3}$ was exceeded under the experimental conditions tested. These two phenomena had the ability to act as $\mathrm{Ga}$ sinks with respect to the supercritical $\mathrm{NH}_{3}-\mathrm{Na}$ solution, while the Ni-containing components could act as either Ga sinks or sources, depending on the experimental conditions. It is assumed these contributions operate concurrently and therefore each must be carefully considered to correct the apparent solubility values determined purely by mass change of the GaN charge.

In the following, each error contribution will be independently discussed. An apparent GaN solubility curve will be presented based on the mass change of the GaN charge. Additionally, temperature-dependent error contributions are provided in Ga solubility plots, for which positive values indicate that $\mathrm{Ga}$ was added to the supercritical $\mathrm{NH}_{3}-\mathrm{Na}$ solution, and negative values indicate that $\mathrm{Ga}$ was removed from the supercritical $\mathrm{NH}_{3}-\mathrm{Na}$ solution. The cumulative effect of all Ga solubility error contributions is given in a refined GaN solubility curve as a function of fluid temperature in Figure 13.

\subsection{Gravimetric GaN Charge Measurements}

The determination of GaN solubility as a function of temperature by exclusively monitoring mass change of the GaN charge, as is conventionally done for gravimetric experiments, can be calculated according to Equation 2, which normalizes $\mathrm{GaN}$ solubility by the $\mathrm{NH}_{3}$ fill. This is the 
proper normalization for systems in which the mineralizer has exceeded its solubility limit in supercritical $\mathrm{NH}_{3}$, as is the case for $\mathrm{Na}$ in this study, in which the $\mathrm{Na}$ amount dissolved in supercritical $\mathrm{NH}_{3}$ is not equivalent to the fill $\mathrm{Na}$. The apparent $\mathrm{GaN}$ solubility, determined in this fashion, is plotted as a function of fluid temperature in Figure 3.

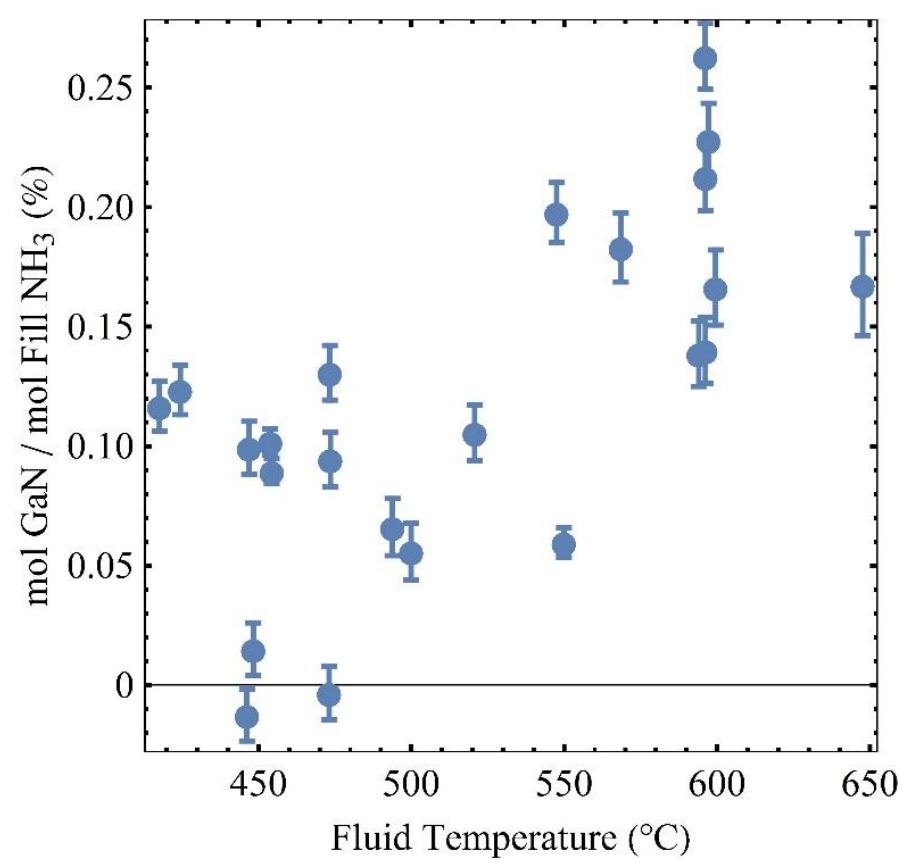

Figure 3. Apparent $\mathrm{GaN}$ solubility, normalized by fill $\mathrm{NH}_{3}$, in supercritical $\mathrm{NH} 3-\mathrm{Na}$ solutions as a function of fluid temperature, as determined exclusively by the mass change of polycrystalline GaN charge.

By only considering the mass change of the $\mathrm{GaN}$ charge, the solubility of $\mathrm{GaN}$ in the supercritical NH3-Na solution would appear to be normal. There is significant scatter in the data, well in excess of the anticipated experimental error range (indicated as error bars, typically $+/-$ $0.02 \%$ ). Additionally, mass gains on the $\mathrm{GaN}$ charge were sometimes measured at low fluid temperatures, indicating that $\mathrm{GaN}$ was deposited on the charge during these experiments. There should have been no driving force for $\mathrm{GaN}$ deposition on the charge from the supercritical $\mathrm{NH}_{3^{-}}$ $\mathrm{Na}$ solution due to the presumed equilibrium between the charge and the solution under isothermal conditions. This implies that $\mathrm{Ga}$ (or $\mathrm{GaN}$ ) had to exist at a higher activity somewhere 
else in the system, thereby acting as a $\mathrm{Ga}($ or $\mathrm{GaN}$ ) source which supersaturated the solution, allowing for $\mathrm{GaN}$ deposition on the charge. This $\mathrm{Ga}$ (or $\mathrm{GaN}$ ) source behavior is examined in the following.

\subsection{Gallium in Nickel-Containing Components}

The previous gravimetric studies of GaN solubility in the basic ammonothermal environment were performed in Ni-based autoclaves, and as such one may speculate on the possibility of Ga$\mathrm{Ni}$ compound formation, given known binary Ga-Ni phase behavior at temperatures relevant to ammonothermal growth [27]. A study on the corrosion behavior of Inconel 718 autoclaves in the basic ammonothermal growth environment identified the formation of a surface nitride layer on the inner autoclave wall using EDX, but the authors did not report on the presence of Ga in the alloy [28]. Ga was however identified in all Ni-containing components in this study, and an attempt to quantify the effect of Ga-alloying in each component on the solubility of GaN in supercritical $\mathrm{NH}_{3}-\mathrm{Na}$ solutions was conducted.

\subsubsection{Gallium in GaN-Containing Basket (Ni and 80-20 Ni-Cr wires)}

EDX analysis was performed on $80-20 \mathrm{Ni}-\mathrm{Cr}$ wire cross-sections, cut normal to the axial direction of the wire. The wires originated from woven mesh parts of two GaN-containing baskets which were exposed to supercritical $\mathrm{NH}_{3}-\mathrm{Na}$ solutions at various temperatures for over 1000 hours each. A representative SEM micrograph near the surface of the Ni-Cr wire is shown in Figure 4a), with the chemical composition measured using EDX given as a function of depth into the wire in Figure 4b). 


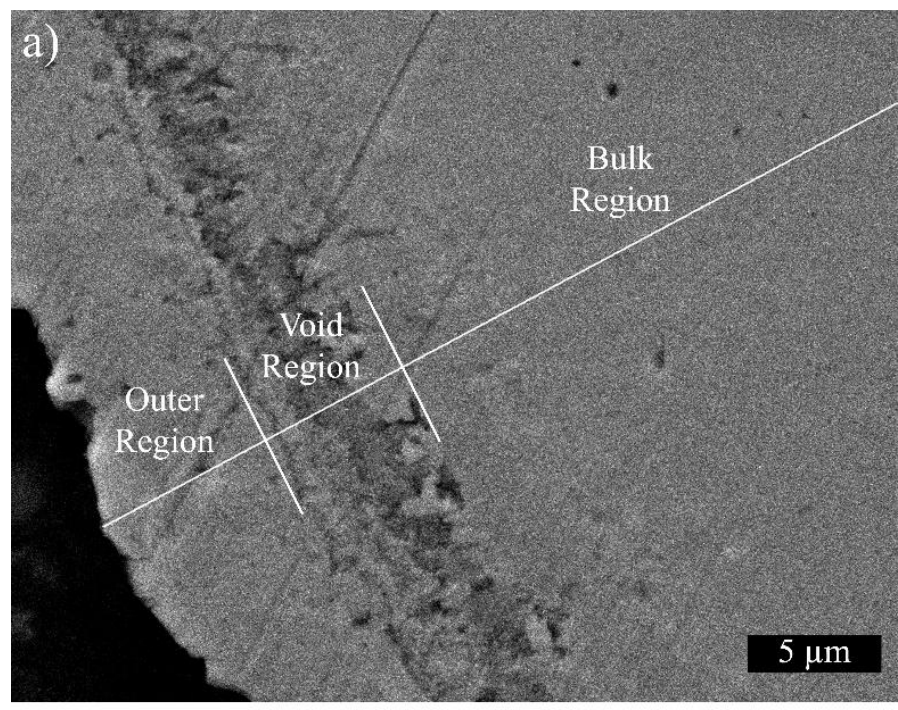

b) $\rightarrow \mathrm{Ni} \longrightarrow \mathrm{Cr} \leadsto \mathrm{N} \longrightarrow \mathrm{Ga}$

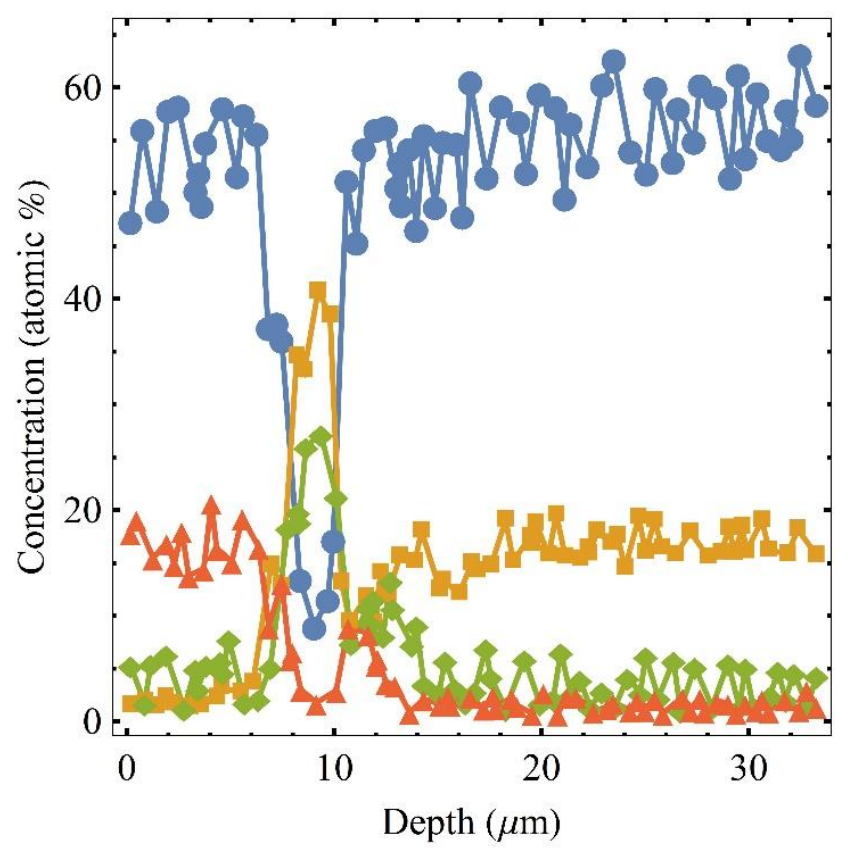

Figure 4. a) Representative Ni-Cr wire cross-section SEM micrograph, showing the path (in white) along which the b) corresponding chemical composition was measured using EDX. For clarity, some dilute contaminate elements are excluded from the plot.

As can be seen in Figure 4, there are three distinct regions of the $\mathrm{Ni}-\mathrm{Cr}$ wire: an outer region near the wire surface, characterized by high relative concentrations of $\mathrm{Ni}$ and $\mathrm{Ga}$; a region of voids roughly 5-10 $\mu \mathrm{m}$ from the wire surface, characterized by high relative concentrations of $\mathrm{Cr}$ and 
$\mathrm{N}$ (and reduced $\mathrm{Ni}$ and $\mathrm{Ga}$ ); and a bulk region with high, relatively uniform concentrations of $\mathrm{Ni}$ and $\mathrm{Cr}$ (and reduced $\mathrm{Ga}$ and $\mathrm{N}$ ). The composition of the outer region indicates that the wire did not continuously nitride, as one would anticipate a decreasing $\mathrm{N}$-concentration gradient into the wire if the process was diffusion driven. What is instead observed is a high $\mathrm{N}$-concentration solely in the void region, which scales with $\mathrm{Cr}$ concentration, suggesting chromium nitride formation. This nitride layer may have formed upon initial exposure to a heavily-nitriding environment. Subsequent experiments may have caused Ga to deposit on the surface and to alloy with $\mathrm{Ni}$ which diffused from the bulk through the nitride layer (possibly forming the voids shown in Figure 4). While further investigations are needed to determine the underlying mechanisms of initial formation of the $\mathrm{Ga}$ and $\mathrm{Ni}$-containing surface, its presence is unambiguous evidence that $\mathrm{Ga}$ and Ni alloy under ammonothermal conditions.

For this study, it is assumed that $\mathrm{Ni}$ is not soluble in the $\mathrm{NH}_{3}-\mathrm{Na}$ solution, that the Ga-Ni alloy presents a considerable diffusion barrier for inward $\mathrm{N}$ diffusion (to form additional chromium nitride), and that the Ga-Ni alloy was already present for the first solubility experiments, as the baskets were exposed to supercritical $\mathrm{NH}_{3}-\mathrm{Na}$ solutions containing Ga-species prior to this study for at least 450 hours. With these assumptions, the mass change of the GaN-containing basket can be completely associated with Ga uptake or loss to/from the Ga-Ni alloy. 


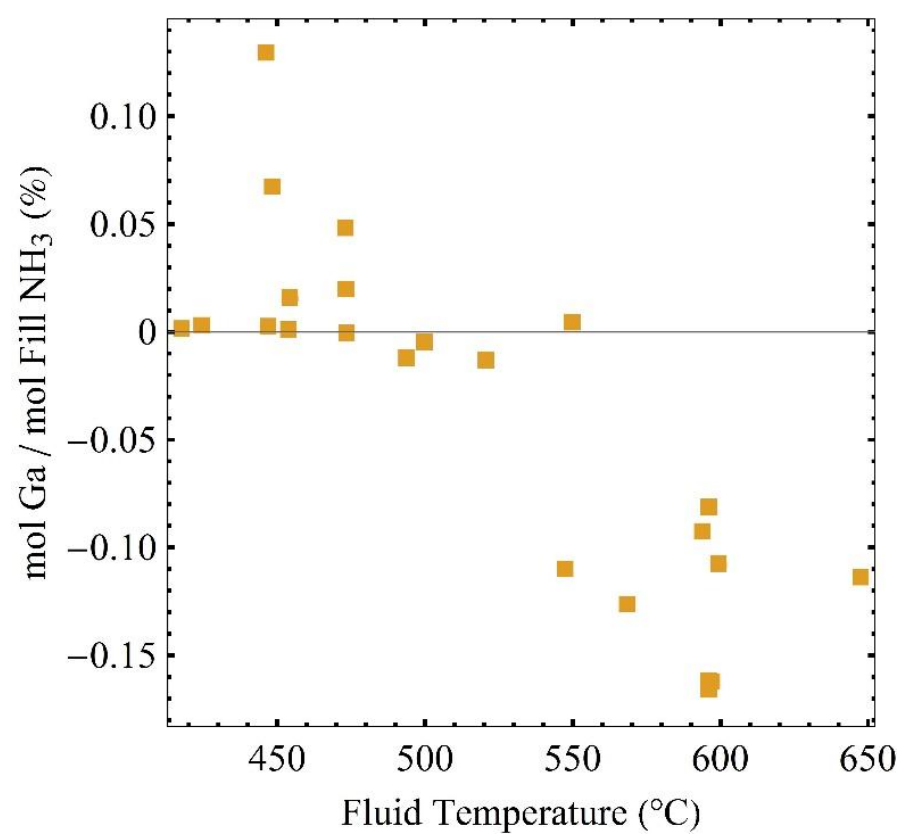

Figure 5. Ga solubility, normalized by fill $\mathrm{NH}_{3}$, added to (or subtracted from, if negative) the supercritical $\mathrm{NH}_{3}-\mathrm{Na}$ solution as a function of fluid temperature, based on the mass change of the GaN-containing basket.

Figure 5 presents the moles of $\mathrm{Ga}$, normalized by fill $\mathrm{NH}_{3}$, added to (or subtracted from, if negative) the supercritical $\mathrm{NH}_{3}-\mathrm{Na}$ solution based on the mass change of the GaN-containing basket for each experiment. It is reasonable to assume that the extent to which dissolved Ga from the supercritical $\mathrm{NH}_{3}-\mathrm{Na}$ solution can alloy with the Ga-Ni surface of the wire is dependent on at least three factors (if diffusion-limited): the temperature of the system (this dependence is shown in Figure 5), the exposure time of the wire to the solution, and the difference in chemical potential between $\mathrm{Ga}$ in the solution and $\mathrm{Ga}$ in the wire. Additional experiments are required to elucidate the effect of exposure time on the mass change of the GaN-containing basket. It is more complicated to understand the chemical potential gradient of $\mathrm{Ga}$ between the solution and the wire, as one would need a priori knowledge of the solubility of $\mathrm{Ga}$ in supercritical $\mathrm{NH}_{3}-\mathrm{Na}$ solution. However, the effect of this chemical potential gradient can be thought of qualitatively in terms of a memory effect. All previous experiments dictate how much Ga has alloyed with the 
GaN-containing basket prior to each subsequent experiment, thereby fixing the chemical potential of $\mathrm{Ga}$ in the wire once the wire reaches thermal equilibrium with the solution. Therefore, the scatter observed in Figure 5 is expected, as most solubility experiments were conducted at different soak times, and most GaN-containing baskets were exposed to different temperatures and soak times in previous experiments.

\subsubsection{Gallium in Standoff (Inconel 625)}

Inconel 625 is a Ni-Cr alloy with additional alloying constituents. It contains a comparable amount of $\mathrm{Cr}$ as the $80-20 \mathrm{Ni}-\mathrm{Cr}$ alloy $(\sim 20-23 \mathrm{wt}$. \%) and as such it could behave similarly to the previously discussed 80-20 Ni-Cr wire. EDX analysis of an Inconel 625 standoff crosssection sample suggests Ga-alloying occurred in the surface layer (see Figure 6).

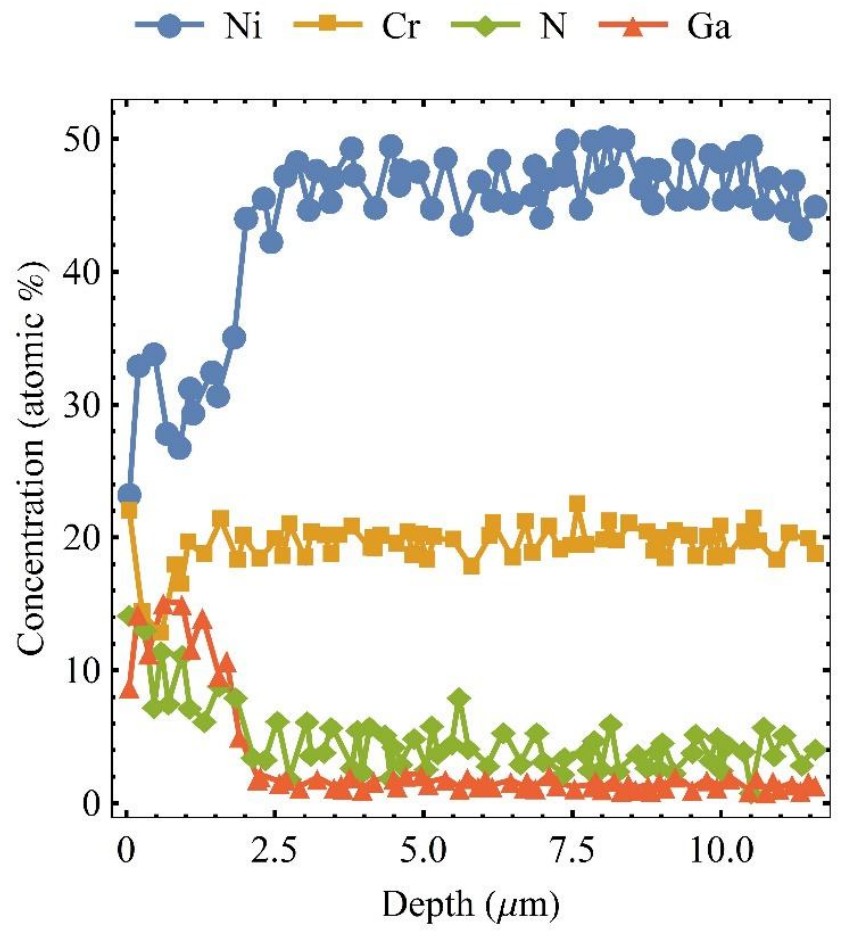

Figure 6. Representative chemical composition (measured by EDX) of an Inconel 625 sample cross-section, which was exposed to supercritical $\mathrm{NH}_{3}-\mathrm{Na}$ solutions with dissolved $\mathrm{Ga}$. For clarity, some dilute alloying elements are excluded from the plot. 
In contrast to the $80-20 \mathrm{Ni}-\mathrm{Cr}$ wire, the Inconel 625 material exhibited a smooth tail of $\mathrm{N}$ into the bulk and a depletion of $\mathrm{Ni}$ and $\mathrm{Cr}$ on the surface. As continuous nitriding of Inconel 625 may be possible, mass changes of the Inconel 625 standoff can be attributed to Ga uptake or depletion from/to the supercritical $\mathrm{NH}_{3}-\mathrm{Na}$ solution, $\mathrm{N}$ uptake, and leeching of alloying elements into the $\mathrm{NH}_{3}-\mathrm{Na}$ solution. Given the uniform distribution of alloying elements as a function of depth (not shown in Figure 6) and the larger atomic mass of $\mathrm{Ga}$ as compared to $\mathrm{N}$, it will be assumed for the purposes of this study that any mass change of the Inconel 625 standoff is only due to Ga uptake or depletion.

Figure 7 presents the moles of $\mathrm{Ga}$, normalized by fill $\mathrm{NH}_{3}$, added to (or subtracted from, if negative) the supercritical $\mathrm{NH}_{3}-\mathrm{Na}$ solution based on the mass change of the Inconel 625 standoff for each experiment. As is evident in comparing Figure 5 and Figure 7, the effect is substantially smaller than the contributions from the GaN-containing basket, partially due to the $\sim 20-40 \mathrm{x}$ smaller surface area of the standoffs. There is also scatter in the temperature dependence of Ga solubility attributed to the standoff, which can once again be explained by the memory effect of $\mathrm{Ga}$ in the standoff from previous experiments, and from various soak times at different temperatures. 


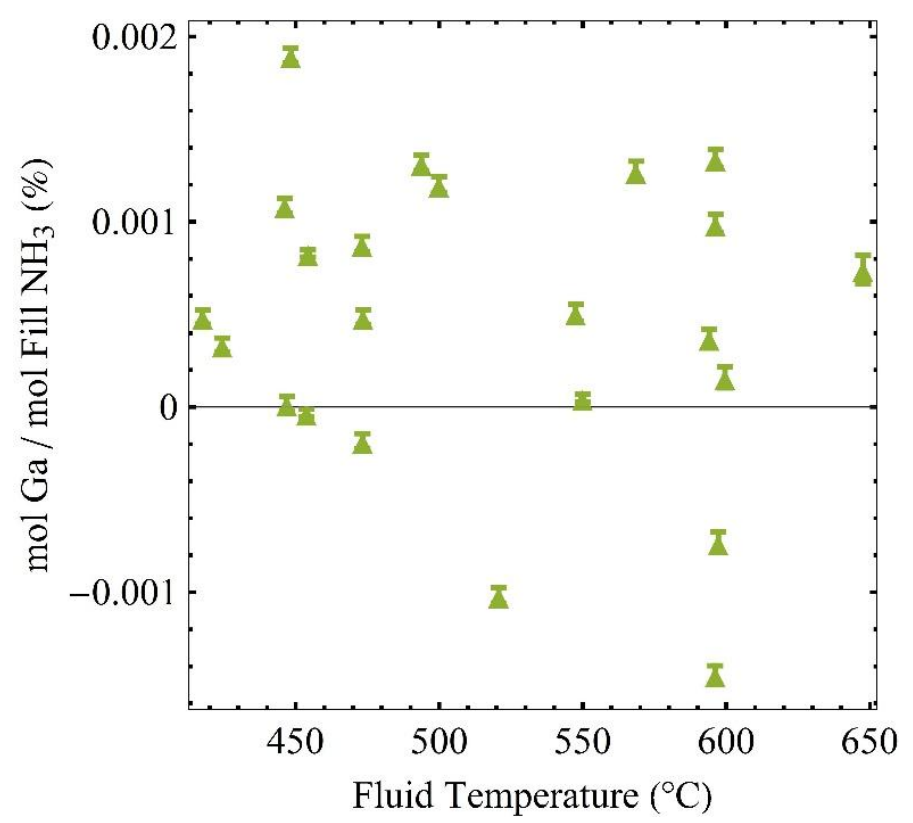

Figure 7. Ga solubility, normalized by fill $\mathrm{NH}_{3}$, added to (or subtracted from, if negative) the supercritical $\mathrm{NH}_{3}-\mathrm{Na}$ solution as a function of fluid temperature, based on the mass change of the Inconel 625 standoff.

\subsubsection{Gallium in Autoclave Wall (Rene 41)}

Experimental verification of the Ga-alloying effect in Rene 41 was conducted to determine if correction to the apparent $\mathrm{GaN}$ solubility curve was necessary for the autoclave wall. After conducting a $600{ }^{\circ} \mathrm{C}$ solubility experiment, an autoclave was neutralized, rinsed with deionized water and isopropanol, and allowed to dry. A pure Ni foil ( $99.5 \%$ metals basis purity) was then placed inside the empty autoclave and re-run at the previous experimental conditions $\left(600{ }^{\circ} \mathrm{C}\right.$, 164 hour soak time, 20:1 molar $\mathrm{NH}_{3}: \mathrm{Na}$ fill ratio) to act as a $\mathrm{Ga}$ sink for dissolved $\mathrm{Ga}$ from the autoclave wall. The mass change of the Ni foil was $+47.04 \mathrm{mg}$. EDX analysis was performed on a cross-section of the Ni foil sample (see Figure 8). It is evident that the mass increase of the Ni is primarily due to Ga-uptake, which could only have been sourced from the Rene 41 autoclave wall in this experiment. 


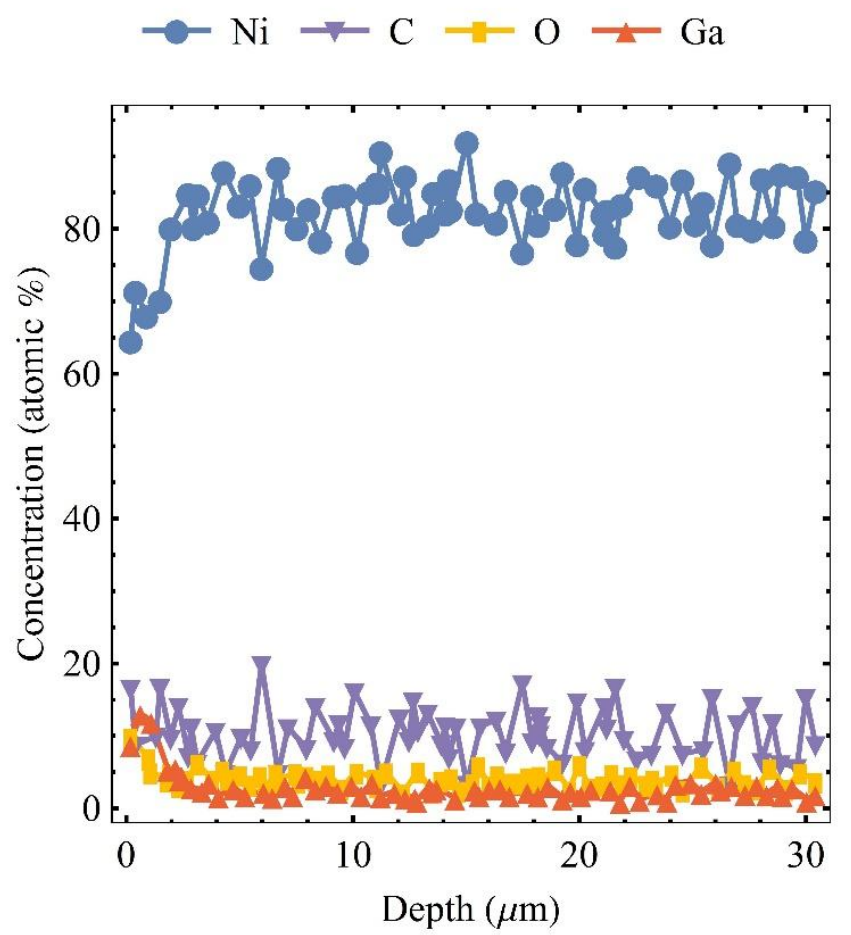

Figure 8. Representative chemical composition (measured by EDX) of a Ni foil sample cross-section, which was exposed to supercritical $\mathrm{NH}_{3}-\mathrm{Na}$ solution at $600{ }^{\circ} \mathrm{C}$. The Ga observed in the surface layer could only originate from the autoclave wall. For clarity, some dilute contaminate elements are excluded from the plot.

Knowledge of the memory effect of Ga in the autoclave wall was only gained towards the end of this study, and mass change of the autoclave can be attributed to several factors, making it impossible to determine its effect on Ga solubility by direct mass change measurements of the autoclave. Given accurate information on the mass change of the Inconel 625 standoff, and assuming the Rene 41 autoclave wall material behaves comparably (they have similar amounts of Ni: 55-69 wt. \% and 47-59 wt. \%; and similar amounts of Cr: 20-23 wt. \% and 18-20 wt. $\%$, for Inconel 625 and Rene 41, respectively), the mass change of the Inconel 625 standoff was extrapolated to the nominal surface area of the autoclave inner wall for each experiment. Estimated errors for this extrapolation are $\sim 50 \%$ due to the surface roughness of both components. The moles of $\mathrm{Ga}$, normalized by fill $\mathrm{NH}_{3}$, added to (or subtracted from, if negative) 
the supercritical $\mathrm{NH}_{3}-\mathrm{Na}$ solution based on this extrapolation are shown in Figure 9. An experimentally-determined lower bound estimation of $\sim 0.05$ mol. $\% \mathrm{Ga}$ (normalized by fill $\mathrm{NH}_{3}$ ) dissolved in the autoclave wall from the supercritical $\mathrm{NH}_{3}-\mathrm{Na}$ solution at $600{ }^{\circ} \mathrm{C}$ can be calculated using the mass gain of the Ni foil, as previously described. Therefore, it is likely that the Ga solubility plotted in Figure 9 is an underestimation as it pertains to autoclave wall effects.

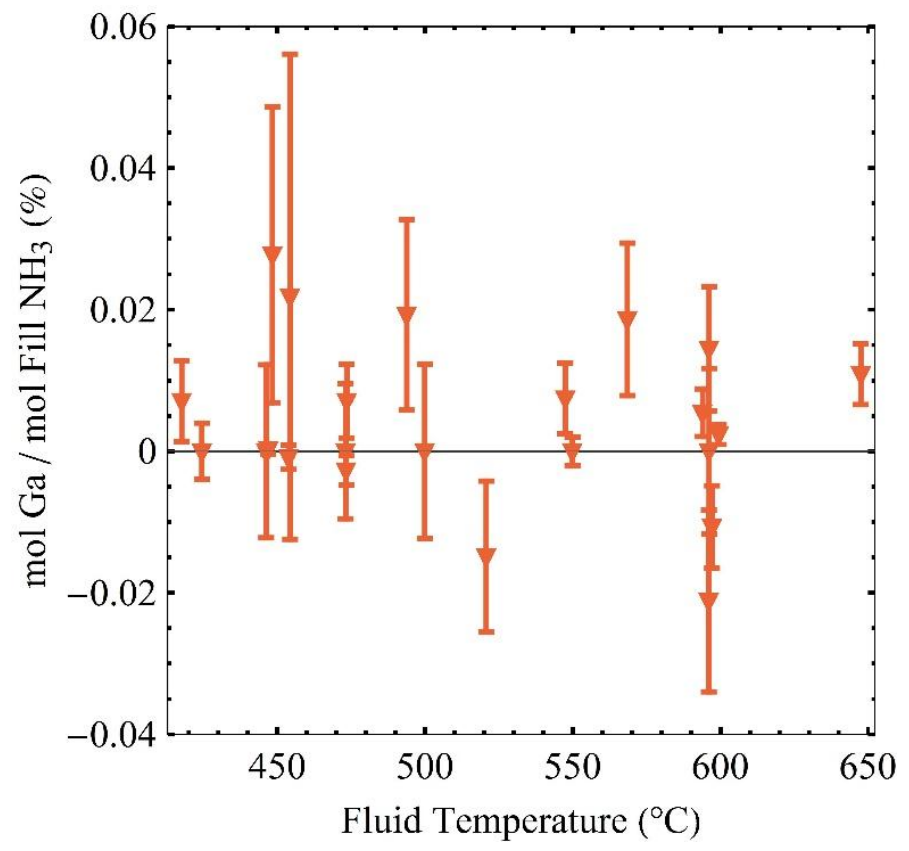

Figure 9. Ga solubility, normalized by fill $\mathrm{NH}_{3}$, added to (or subtracted from, if negative) the supercritical $\mathrm{NH}_{3}-\mathrm{Na}$ solution as a function of fluid temperature, based on the mass change of the Inconel 625 Standoff which was extrapolated to the surface area of the Rene 41 Autoclave wall.

It should be noted that the cleaning process of the autoclave after each experiment was inconsistent: for certain runs abrasives were used to remove the nitride surface layers, whereas for others abrasives were not used. Removal of the surface layer is anticipated to remove an unverified amount of retained $\mathrm{Ga}$ from the autoclave wall. For runs performed in previously abrasive-cleaned autoclaves, the autoclave wall was not treated as a Ga-source for the 
supercritical $\mathrm{NH}_{3}-\mathrm{Na}$ solution, and as such the autoclave wall extrapolation was taken as 0 in Figure 9.

\subsection{Gallium in Sodium-Rich Phase}

Although the solubility of $\mathrm{Na}$ in liquid $\mathrm{NH}_{3}$ has been extensively studied, there has been no published effort to measure the solubility of $\mathrm{Na}$ in supercritical $\mathrm{NH}_{3}$ [29][30]. The following evidence collected in this study would suggest that the $20: 1 \mathrm{NH}_{3}: \mathrm{Na}$ molar filling concentration used in these GaN solubility measurements exceeded the solubility limit of $\mathrm{Na}$ in supercritical $\mathrm{NH}_{3}$ under the explored conditions, thereby allowing for the presence of a Na-rich second phase (most likely through the reaction of $\mathrm{Na}$ with $\mathrm{NH}_{3}$ to form $\mathrm{NaNH}_{2}$ ) in the autoclave during each experiment. Due to the rapid evacuation $(<1$ second) of the autoclave at elevated temperatures at the conclusion of each experiment, the corresponding momentum of the supercritical $\mathrm{NH}_{3}-\mathrm{Na}$ solution being evacuated, and the lack of visible streaking down the autoclave wall (which would be present if molten Na-species came out of solution and fell to the bottom of the autoclave), we believe the Na-containing powder was present in the liquid state during each experiment. This material present at the bottom of the autoclave (on the order of grams) excludes the small amount of Na-containing powder (on the order of milligrams) which was observed in the tubing connecting the autoclave to the line filter, and the Na-containing powder in the line filter itself (on the order of tens to hundreds of milligrams). The Na-containing powder observed in the tubing was thought to be transported from the autoclave during each experiment due to the large temperature gradient between the autoclave and the initial length of tubing. However, the Nacontaining powder in the line filter was thought to be crystallized from the rapid evacuation process, as the temperature gradient between the final length of tubing and the line filter during 
the experiment was small, and the only interaction of hot gas effluent with the high surface area line filter occurred during the evacuation process. Further evidence for the presence of the Narich second phase includes consistently observed changes in surface coloration across a distinct interface on the Inconel 625 standoff, which varies in height with varying fill Na content. Similar observations suggest that this second phase is present during growth experiments as well.

As the ability of the Na-rich phase to absorb Ga is unknown, six dedicated experiments at different temperatures were performed to collect the Na-rich powder post-run. ICP analysis was then conducted on two sample dilutions from each powder, so as to determine the precision of the Ga-concentration measurement of the tool. The moles of Ga dissolved in the Na-rich powder (determined from the ICP Ga-concentration measurement and the mass of the powder, normalized by the moles of fill $\mathrm{Na}$ ) is plotted as a function of the fluid temperature of each of these six experiments in Figure 10.

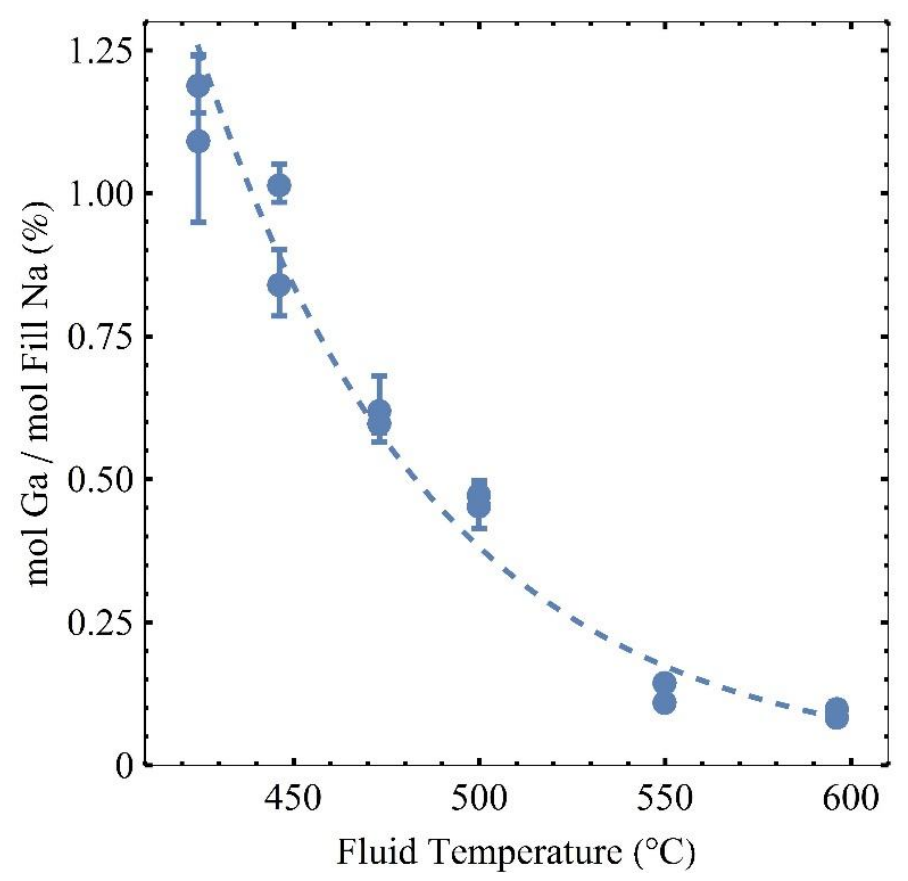

Figure 10. Ga solubility in the Na-rich powder, normalized by fill $\mathrm{Na}$, as a function of the fluid temperature. The dashed line provides an exponential fit to the data. 
It should be noted that the $550{ }^{\circ} \mathrm{C}$ experiment was conducted in the large volume autoclave, while all other experiments in this series were conducted in the small volume autoclaves. Additionally, the mass of $\mathrm{Na}$ added to each autoclave was adjusted to provide a nominal $\mathrm{NH}_{3}: \mathrm{Na}$ molar fill ratio of $20: 1$, with the fill $\mathrm{NH}_{3}$ being adjusted to target a nominal total system peak pressure of $200 \mathrm{MPa}$. As such, the mass of $\mathrm{Na}$ added to the autoclaves was different for each temperature. It is apparent from Figure 10 that $\mathrm{Ga}$ dissolution in the Na-rich phase has an intensive, exponential correlation with temperature, indicating Arrhenius behavior.

It is assumed that the measured Ga dissolution in Figure 10 is repeatable and can be applied (with an exponential fit to the data) to all other solubility experiments. As such, Figure 11 shows the moles of $\mathrm{Ga}$, normalized by fill $\mathrm{NH}_{3}$, lost from the supercritical $\mathrm{NH}_{3}-\mathrm{Na}$ solution (represented by negative values) based on the Na-rich phase sink behavior. The contribution to error in Ga dissolution is estimated from the accuracy of the ICP tool, as this value exceeds the error calculated from the coefficient of determination $\left(\mathrm{R}^{2}\right)$ based on the exponential fit to the data. It should be noted that the mass of the aforementioned Na-containing powder observed in the tubing connecting the autoclave to the line filter was too small to support an appreciable dissolved Ga mass $\left(<10^{-4}\right.$ mol. \% Ga, normalized by fill $\left.\mathrm{NH}_{3}\right)$, and as such its contribution as a Ga sink was neglected in this study. As the Na-containing powder in the line filter was thought to be transported from the solvent during the rapid evacuation process, its contribution as a Ga sink was also neglected. 


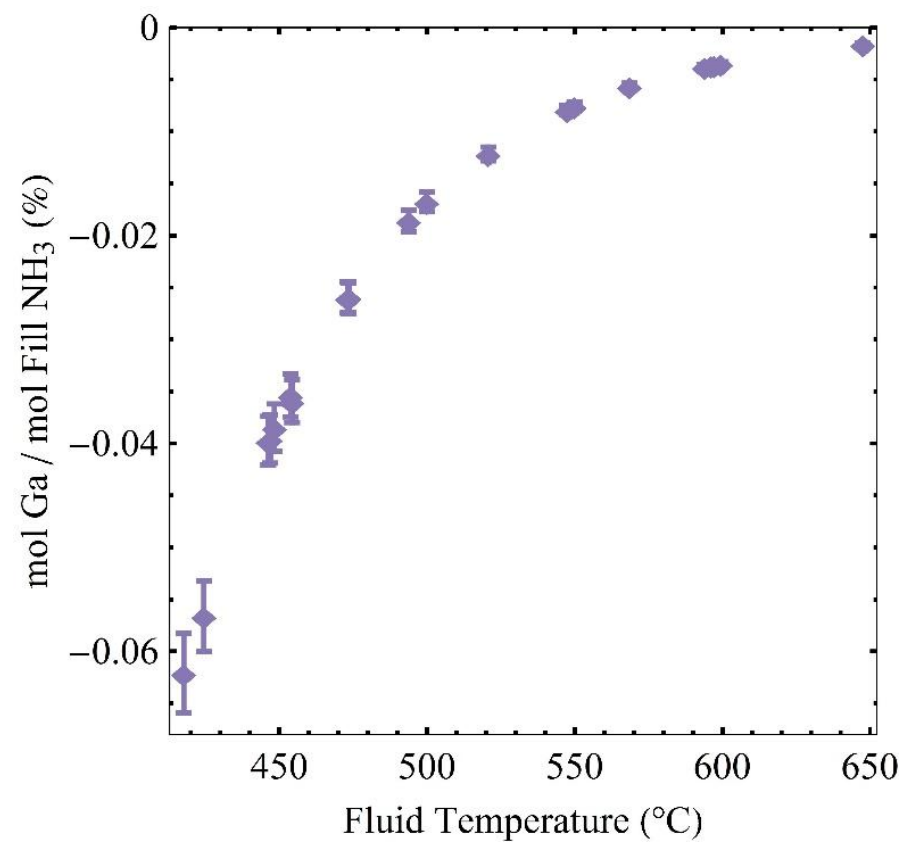

Figure 11. Ga solubility, normalized by fill $\mathrm{NH}_{3}$, lost from the supercritical $\mathrm{NH}_{3}-\mathrm{Na}$ solution (indicated by negative values) as a function of fluid temperature, based on the mass of Ga measured in the Na-rich powder. 


\subsection{GaN Dissolution Kinetics}

Kinetic GaN solubility series were performed as a function of soak time at two temperatures, 450 ${ }^{\circ} \mathrm{C}$ and $600{ }^{\circ} \mathrm{C}$, to ensure that the treatment of the solubility data was correct (including the correction of GaN solubility for all known Ga sources and sinks) and that the supercritical $\mathrm{NH}_{3}$ $\mathrm{Na}$ solutions reached saturation. Figure 12 displays these kinetic series at the specified temperatures.

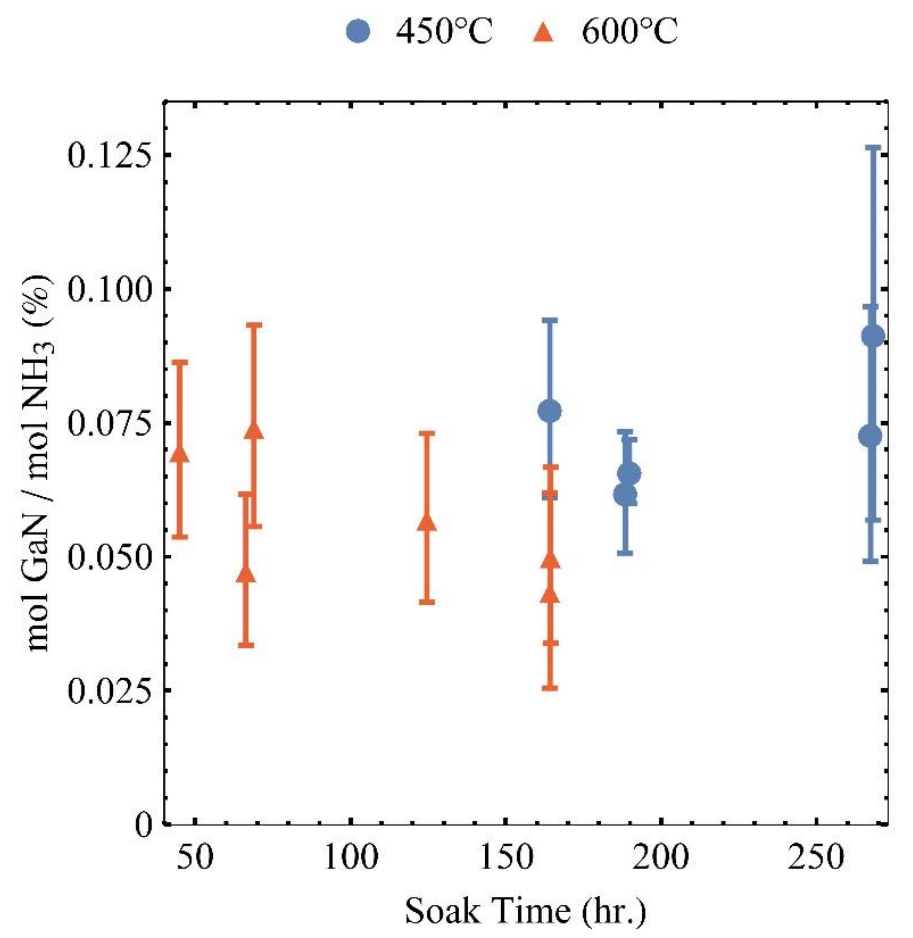

Figure 12. Refined GaN solubility, normalized by fill $\mathrm{NH}_{3}$, as a function of soak time for experiments performed at $450{ }^{\circ} \mathrm{C}$ and $600{ }^{\circ} \mathrm{C}$.

As is apparent in Figure 12, there is no obvious positive correlation of GaN solubility with soak time at either temperature. This suggests that the supercritical $\mathrm{NH}_{3}-\mathrm{Na}$ solution was saturated with $\mathrm{GaN}$ in less than 45 hours for the $600{ }^{\circ} \mathrm{C}$ experiments, and less than 164 hours for the 450 
${ }^{\circ} \mathrm{C}$ experiments. All GaN solubility experiments were therefore conducted for longer durations than these soak times to ensure saturation of the supercritical $\mathrm{NH}_{3}-\mathrm{Na}$ solution. It is possible that that the apparent drop in $\mathrm{GaN}$ solubility with increasing soak time at $600{ }^{\circ} \mathrm{C}$ indicates an overestimate for the Ga-alloying effect in the autoclave wall at long soak times, or an underestimate for this same effect at short soak times.

\subsection{Refined Solubility Curve}

The various contributions of dissolved $\mathrm{Ga}$ to supercritical $\mathrm{NH}_{3}-\mathrm{Na}$ solutions discussed in this work are summed in Figure 13, yielding a more accurate GaN solubility curve.

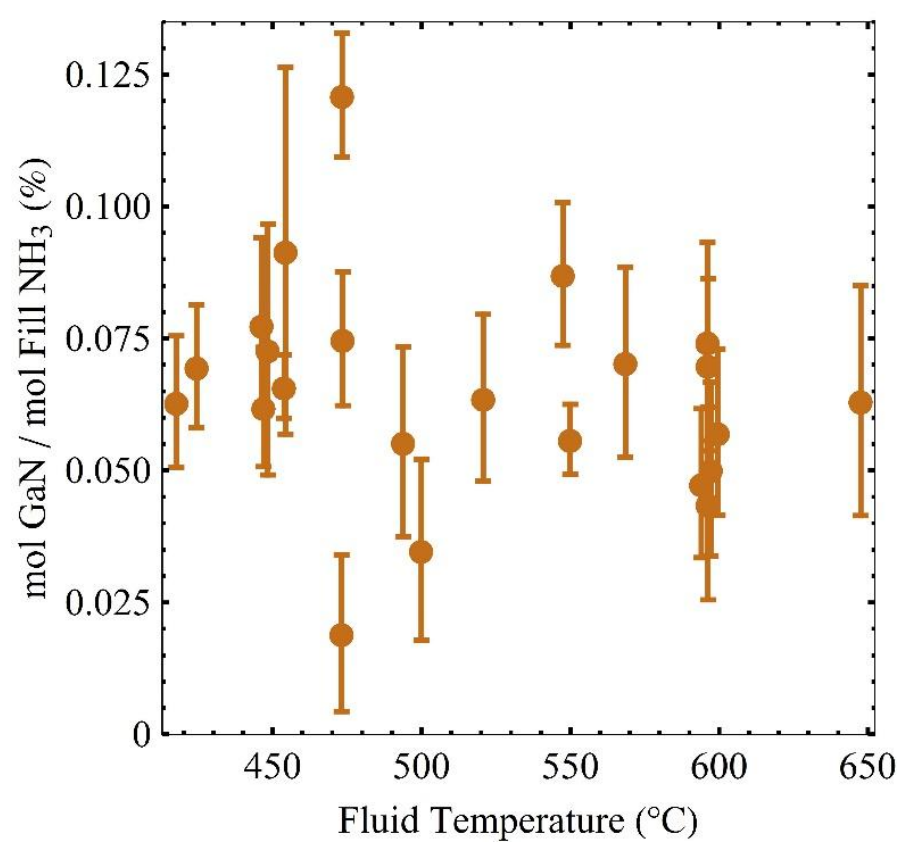

Figure 13. Refined GaN solubility in supercritical NH3-Na solutions, normalized by fill $\mathrm{NH}_{3}$, as a function of fluid temperature, accounting for all discussed data corrections for Ga sources/sinks.

It is apparent from Figure 13 that the GaN solubility magnitude measured in this study is lower than previously measured by Hashimoto et al [20]. Furthermore, a clear retrograde dependence 
of GaN solubility with respect to temperature (as one would anticipate from growth conditions) cannot be determined from Figure 13, due to the scatter and experimental errors in the data. Two dominant, temperature-dependent, competing trends can be noted from Figure 5 and Figure 11, respectively: the GaN-containing basket depletes $\mathrm{Ga}$ from the supercritical $\mathrm{NH}_{3}-\mathrm{Na}$ solutions at temperatures above $475{ }^{\circ} \mathrm{C}$ (while enriching the supercritical $\mathrm{NH}_{3}-\mathrm{Na}$ solutions with Ga below $475^{\circ} \mathrm{C}$ ), and the Na-rich phase depletes less $\mathrm{Ga}$ from the supercritical $\mathrm{NH}_{3}-\mathrm{Na}$ solutions at high temperatures as compared to low temperatures (as dictated by an exponential dependence). These trends act to flatten the refined solubility curve with respect to fluid temperature, as shown in Figure 13.

There are a few possibilities that might result in the scatter observed in Figure 13. As discussed previously, there are memory effects present in all Ni-containing components in the system. These effects were explicitly measured for the GaN-containing basket and the Inconel 625 standoff, but not for the autoclave wall. Evidence was presented to suggest that the extrapolation of the Inconel 625 standoff was insufficient to correct for uptake/depletion of Ga to/from the Rene 41 autoclave wall, thus it is likely that Ga-alloying of the autoclave wall played a significant factor in this scatter. It is also possible that the extrapolation used for the $\mathrm{Ga}$ dissolution in the Na-rich phase was not sufficiently accurate to correct all of the solubility data with. The experiments used to generate the Na-rich powder, which was further analyzed using ICP as the basis for this extrapolation, were all conducted in autoclaves which were treated with abrasives prior to use. It is possible that some additional Ga from the autoclave wall was dissolved in the Na-rich phase in experiments with autoclaves not treated with abrasives.

The evolution of $\mathrm{H}_{2}$ through the anticipated formation of $\mathrm{NaNH}_{2}, \mathrm{NH}_{3}$ decomposition, and related loss of $\mathrm{H}_{2}$ from the system due to outward diffusion at higher temperatures were not 
considered for this study and could also affect the results. While all solubility data for this study was normalized by the initial fill $\mathrm{NH}_{3}$, further investigations are needed to determine the equilibrium chemical composition of the supercritical $\mathrm{NH}_{3}-\mathrm{Na}$ solution. This will enable the determination of true GaN solubility with respect to $\mathrm{Na}$ concentration in the supercritical fluid, and with respect to the equilibrium solvent composition $\left(\mathrm{NH}_{3}, \mathrm{~N}_{2}\right.$, and $\left.\mathrm{H}_{2}\right)$.

\section{Summary}

An accurate determination of $\mathrm{GaN}$ solubility in supercritical $\mathrm{NH}_{3}-\mathrm{Na}$ solutions has been reported through the course of 23 gravimetric solubility experiments under ammonothermal conditions ( $\mathrm{T}$ $=415-650{ }^{\circ} \mathrm{C}, \mathrm{P} \approx 200 \mathrm{MPa}$, molar $\mathrm{NH}_{3}: \mathrm{Na}$ fill ratio $\left.=20: 1\right)$. The band of GaN solubility, mostly within $0.03-0.10$ mol. \% GaN, normalized by fill $\mathrm{NH}_{3}$, was found to be lower than the previously reported range: $0.023-0.245 \mathrm{~mol}$. $\% \mathrm{GaN}$, normalized by fill $\mathrm{NH}_{3}$ (for $1.5 \mathrm{~mol} \%$ $\mathrm{NaNH}_{2}$ in $\mathrm{NH}_{3}$ ) [20]. Our analysis indicated that there was no peak in GaN solubility at $600{ }^{\circ} \mathrm{C}$ (within the precision of our measurements), which was previously reported in the $\mathrm{NaNH}_{2}$ study [20]. The target total system peak pressure in our study was $200 \mathrm{MPa}$, whereas the previous $\mathrm{NaNH}_{2}$ study targeted $83 \mathrm{MPa}$, which could also impact the disparity in solubility results [20].

Two previously unreported error sources were identified in the gravimetric determination of GaN

solubility in the $\mathrm{NH}_{3}-\mathrm{Na}$ system under the explored ammonothermal conditions: Ga-alloying of Ni-containing components (identified using EDX), and Ga dissolution in the Na-rich, second phase (identified using ICP). In general, Ni-containing components depleted Ga from the supercritical $\mathrm{NH}_{3}-\mathrm{Na}$ solution at high temperatures $\left(>475{ }^{\circ} \mathrm{C}\right)$, while the Na-rich phase depleted more $\mathrm{Ga}$ from the $\mathrm{NH}_{3}-\mathrm{Na}$ solution at lower temperatures than at higher temperatures. The aforementioned error sources, and corrections thereof, are thought to be mostly responsible for the accurate refinement of the gravimetric solubility curve from an operational standpoint (i.e. 
excluding solubility dependence on the equilibrium solvent composition). While new sources of error cannot be ruled out, the observed scatter which was introduced in the refined GaN solubility curve is thought to be a result of the inability to measure Ga-alloying of the exposed autoclave wall for each experiment. This led to our inability to measure a clear temperature dependence of GaN solubility.

\section{Acknowledgments}

The authors acknowledge the support from the Solid State Lighting and Energy Electronics Center at the University of California, Santa Barbara, and the Materials Research Laboratory TEMPO and Microscopy Facilities, which are supported by the MRSEC Program of the National Science Foundation under Award No. DMR 1121053. The first author would also like to acknowledge Prof. Michael Doherty for his illuminating insight on reaction and phase equilibria,

Thomas F. Malkowski and Paul Von Dollen for their discussions on thermodynamics, and Rob Rhein for his assistance in preparing samples for EDX analysis.

\section{References}

[1] C. Weisbuch, M. Piccardo, L. Martinelli, J. Iveland, J. Peretti, and J. S. Speck, "The efficiency challenge of nitride light-emitting diodes for lighting," Phys. Status Solidi, vol. 212, no. 5, pp. 899-913, 2015.

[2] C.C. Pan, S. Tanaka, F. Wu, Y. Zhao, J. S. Speck, S. Nakamura, S. P. DenBaars, and D. Feezell, "High-Power, Low-Efficiency-Droop Semipolar (2021) Single-Quantum-Well Blue LightEmitting Diodes," Appl. Phys. Express, vol. 5, no. 6, p. 062103, 2012.

[3] J. S. Speck, S. F. Chichibu, and G. Editors, "N onpolar and Semipolar Group III Materials," vol. 34, no. May, 2009.

[4] A. Inoue, R. Kato, A. Yamada, and T. Yokogawa, "Extremely high current density over 1000 A / $\mathrm{cm} 2$ operation in m-plane GaN small size LEDs with low efficiency droop and method for controlling radiation pattern and polarization Akira Inoue , Ryo Kato , Atsushi Yamada , and Toshiya Yokogawa,” 2012 Int. Electron Devices Conf., pp. 621-624, 2012.

[5] J. S. Speck and S. J. Rosner, "The role of threading dislocations in the physical properties of GaN and its alloys," Phys. B Condens. Matter, vol. 273-274, pp. 24-32, Dec. 1999. 
[6] K. Motoki, "Development of Gallium Nitride Substrates," SEI Tech. Rev., no. 70, pp. 28-35, 2010.

[7] Y. Mikawa, T. Ishinabe, S. Kawabata, and T. Mochizuki, "Ammonothermal Growth of Polar and Non-polar Bulk GaN Crystal,” vol. 9363, pp. 1-6, 2015.

[8] D. Ehrentraut, R. T. Pakalapati, D. S. Kamber, W. Jiang, D. W. Pocius, B. C. Downey, M. Mclaurin, and M. P. D. E. Â, "High Quality , Low Cost Ammonothermal Bulk GaN Substrates," vol. 52, pp. 1-4, 2013.

[9] Q. Bao, M. Saito, K. Hazu, Y. Kagamitani, K. Kurimoto, D. Tomida, K. Qiao, T. Ishiguro, C. Yokoyama, and S. F. Chichibu, "Ammonothermal growth of GaN on a self-nucleated GaN seed crystal," J. Cryst. Growth, vol. 404, pp. 168-171, Oct. 2014.

[10] Y. Kagamitani, D. Ehrentraut, A. Yoshikawa, N. Hoshino, T. Fukuda, S. Kawabata, and K. Inaba, "Ammonothermal Epitaxy of Thick GaN Film Using NH 4 Cl Mineralizer," Jpn. J. Appl. Phys., vol. 45, no. 5A, pp. 4018-4020, May 2006.

[11] K. Yoshida, K. Aoki, and T. Fukuda, "High-temperature acidic ammonothermal method for GaN crystal growth," J. Cryst. Growth, vol. 393, pp. 93-97, May 2014.

[12] S. Pimputkar, S. Kawabata, J. S. Speck, and S. Nakamura, "Improved growth rates and purity of basic ammonothermal GaN,” J. Cryst. Growth, vol. 403, pp. 7-17, Oct. 2014.

[13] K. Fujito, S. Kubo, and I. Fujimura, "Development of Bulk GaN Crystals and Nonpolar/Semipolar Substrates by HVPE," MRS Bull., vol. 34, pp. 313-317, 2009.

[14] S. Schimmel, M. Lindner, T. G. Steigerwald, B. Hertweck, T. M. M. Richter, U. Künecke, N. S. a. Alt, R. Niewa, E. Schlücker, and P. J. Wellmann, "Determination of GaN solubility in supercritical ammonia with $\mathrm{NH} 4 \mathrm{~F}$ and $\mathrm{NH} 4 \mathrm{Cl}$ mineralizer by in situ $\mathrm{x}$-ray imaging of crystal dissolution," J. Cryst. Growth, vol. 418, pp. 64-69, May 2015.

[15] D. Ehrentraut, Y. Kagamitani, C. Yokoyama, and T. Fukuda, "Physico-chemical features of the acid ammonothermal growth of GaN," J. Cryst. Growth, vol. 310, no. 5, pp. 891-895, Mar. 2008.

[16] D. Tomida, K. Kuroda, N. Hoshino, K. Suzuki, Y. Kagamitani, T. Ishiguro, T. Fukuda, and C. Yokoyama, "Solubility of GaN in supercritical ammonia with ammonium chloride as a mineralizer," J. Cryst. Growth, vol. 312, no. 21, pp. 3161-3164, Oct. 2010.

[17] D. Tomida, T. Kuribayashi, K. Suzuki, Y. Kagamitani, T. Ishiguro, T. Fukuda, and C. Yokoyama, "Effect of halogen species of acidic mineralizer on solubility of GaN in supercritical ammonia," $J$. Cryst. Growth, vol. 325, no. 1, pp. 52-54, Jun. 2011.

[18] R. Dwilinski, R. Doradzinski, J. Garczynski, L. Sierzputowski, a Puchalski, Y. Kanbara, K. Yagi, H. Minakuchi, and H. Hayashi, "Excellent crystallinity of truly bulk ammonothermal GaN," $J$. Cryst. Growth, vol. 310, no. 17, pp. 3911-3916, Aug. 2008.

[19] B. Wang, M. J. Callahan, K. D. Rakes, L. O. Bouthillette, S.-Q. Wang, D. F. Bliss, and J. W. Kolis, "Ammonothermal growth of GaN crystals in alkaline solutions," J. Cryst. Growth, vol. 287, no. 2, pp. 376-380, Jan. 2006.

[20] T. Hashimoto, M. Saito, K. Fujito, F. Wu, J. S. Speck, and S. Nakamura, "Seeded growth of GaN by the basic ammonothermal method," J. Cryst. Growth, vol. 305, no. 2, pp. 311-316, Jul. 2007.

[21] Q. Bao, M. Saito, K. Hazu, K. Furusawa, Y. Kagamitani, R. Kayano, D. Tomida, K. Qiao, T. Ishiguro, C. Yokoyama, and S. F. Chichibu, "Ammonothermal Crystal Growth of GaN Using an NH 4 F Mineralizer,” Crys Grow Des, vol. 13, p. 4158, 2013. 
[22] R. Juza, H. H. Weber, and K. Opp, “Kristallstruktur des Natriumamids," Zeitschrift für Anorg. und Allg. Chemie, vol. 284, no. 1, pp. 73-82, 1956.

[23] M. Nagib, H. Kistrup, and H. Jacobs, "Neutron-diffraction by sodium-deuteroamide, NaND2," Atomkernenergie, vol. 26, no. 2, pp. 87-90, 1975.

[24] H. Jacobs and D. Schmidt, "High-pressure ammonolysis in solid-state chemistry," in Current Topics in Materials Science, Volume 8, 1982, pp. 381 - 428.

[25] S. Pimputkar and S. Nakamura, "Decomposition of supercritical ammonia and modeling of supercritical ammonia-nitrogen-hydrogen solutions with applicability toward ammonothermal conditions," J. Supercrit. Fluids, vol. 107, pp. 17-30, 2016.

[26] S. Fernandez-Garrido, G. Koblmuller, E. Calleja, and J. S. Speck, "In situ GaN decomposition analysis by quadrupole mass spectrometry and reflection high-energy electron diffraction," $J$. Appl. Phys., vol. 104, no. 3, p. 033541, 2008.

[27] Predel B., “Ga-Ni ( Gallium-Nickel )," Landolt-Bornstein, vol. Group IV P, no. 5f, pp. 3-6, 1996.

[28] B. Hertweck, T. G. Steigerwald, N. S. A. Alt, and E. Schluecker, "Different corrosion behaviour of autoclaves made of nickel base alloy 718 in ammonobasic and ammonoacidic environments," $J$. Supercrit. Fluids, vol. 95, pp. 158-166, 2014.

[29] O. Ruff and J. Zedner, Ber., vol. 41, p. 1948, 1908.

[30] O. Ruff and E. Geisel, Ber., vol. 39, p. 838, 1906. 